\title{
Proteolytic processing of dynamin by cytoplasmic cathepsin $L$ is a mechanism for proteinuric kidney disease
}

\author{
Sanja Sever, ${ }^{1}$ Mehmet M. Altintas, ${ }^{1}$ Sharif R. Nankoe, ${ }^{1}$ Clemens C. Möller, ${ }^{1}$ David Ko, ${ }^{1}$ \\ Changli Wei, ${ }^{1}$ Joel Henderson, ${ }^{2}$ Elizabetta C. del Re, ${ }^{1}$ Lianne Hsing, ${ }^{3}$ Ann Erickson, ${ }^{4}$ \\ Clemens D. Cohen, ${ }^{5}$ Matthias Kretzler, ${ }^{6}$ Dontscho Kerjaschki,7 Alexander Rudensky, ${ }^{3,8}$ \\ Boris Nikolic, ${ }^{1}$ and Jochen Reiser ${ }^{1}$
}

\begin{abstract}
1Department of Medicine, Nephrology Division and Program in Glomerular Disease, Massachusetts General Hospital (MGH) and Harvard Medical School, Boston, Massachusetts, USA. 'Department of Pathology, Brigham and Women's Hospital, Harvard Medical School, Boston, Massachusetts, USA. ${ }^{3}$ Department of Immunology, University of Washington, Seattle, Washington, USA. ${ }^{4}$ Department of Biochemistry and Biophysics,

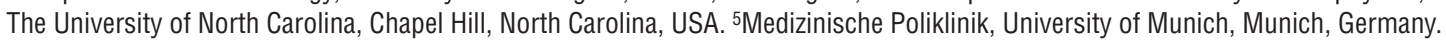

${ }^{6}$ Department of Internal Medicine, Division of Nephrology, University of Michigan Medical School, Ann Arbor, Michigan, USA. ${ }^{7}$ Clinical Institute of Pathology, Vienna Medical University, Vienna, Austria. ${ }^{8}$ Howard Hughes Medical Institute, University of Washington School of Medicine, Seattle, Washington, USA.
\end{abstract}

\begin{abstract}
Kidney podocytes and their foot processes maintain the ultrafiltration barrier and prevent urinary protein loss (proteinuria). Here we show that the GTPase dynamin is essential for podocyte function. During proteinuric kidney disease, induction of cytoplasmic cathepsin $L$ leads to cleavage of dynamin at an evolutionary conserved site, resulting in reorganization of the podocyte actin cytoskeleton and proteinuria. Dynamin mutants that lack the cathepsin L site, or render the cathepsin L site inaccessible through dynamin self-assembly, are resistant to cathepsin $L$ cleavage. When delivered into mice, these mutants restored podocyte function and resolve proteinuria. Our study identifies dynamin as a critical regulator of renal permselectivity that is specifically targeted by proteolysis under pathological conditions.
\end{abstract}

\section{Introduction}

In the US alone, kidney diseases affect some 20 million people, twice as many as it did 2 decades ago. Renal ultrafiltration occurs in glomeruli, specialized structures that ensure permselectivity of the kidney filter so that essential plasma proteins are retained in the blood. A sign of glomerular dysfunction is the loss of protein in the urine (termed proteinuria or nephrotic syndrome if protein loss exceeds $3.5 \mathrm{~g} / \mathrm{d}$ ). Proteinuria often leads to progressive renal failure, eventually requiring dialysis or kidney transplantation (1). Podocytes are specialized cells within the glomerulus that are essential for ultrafiltration (Supplemental Figure 1A; supplemental material available online with this article; doi:10.1172/ JCI32022DS1). Podocytes form foot processes (FPs), highly dynamic cellular extensions that are connected by slit diaphragms. Together with the glomerular basement membrane (GBM) and the glomerular endothelial cells, podocytes form a key component of the kidney permeability barrier. Most forms of proteinuria are characterized by a reduction of podocyte membrane extensions in number and size as well as transformation of podocyte FPs into a band of cytoplasm (referred to as FP effacement). Familial mutations underlie only a small percentage of kidney diseases (2) and therefore do not readily explain the molecular mechanisms underlying the far more common acquired causes of FP effacement and proteinuria. In this study, we show that dynamin is essential to maintain the filtration barrier in kidneys due to a role in regulating actin dynamics in podocytes. We further demonstrate that CatL is

Nonstandard abbreviations used: CatL, cathepsin L; FP, foot process; PAN, puromycin aminonucleoside.

Conflict of interest: The authors have declared that no conflict of interest exists. Citation for this article: J. Clin. Invest. 117:2095-2104 (2007). doi:10.1172/JCI32022. responsible for FP effacement. CatL affects podocyte function by cleaving dynamin in the cytoplasm. The cleavage of dynamin by CatL is inhibited when dynamin is induced to self-assemble. Gene delivery of dynamin mutants that are prone to self-assemble into higher-order structures, or that contain a mutated CatL cleavage site, can prevent and reverse podocyte FP effacement and proteinuria in a mouse model of proteinuria.

\section{Results}

Cathepsin L is necessary for podocyte FP effacement and proteinuria in a mouse model. Cathepsin L (CatL) belongs to a subclass of cysteine proteases termed lysosomal cathepsins, which are involved primarily in protein breakdown within the lysosomal compartment. Interestingly, CatL is strongly induced in rodent nephrotic podocytes (3). Moreover, earlier studies showed that inhibitors of cysteine proteases reduced proteinuria in rats, possibly by inhibiting degradation of the GBM (4). Recently, Goulet and colleagues described a novel role for CatL in processing of the CDP/Cux transcription factor in the nucleus during the $\mathrm{S}$ phase (5). Together, these findings raise many possibilities for the potential site of Cat $\mathrm{L}$ action during the pathogenesis of proteinuria, including the cytoplasm. To explore the relevance of CatL in human kidney disease, we examined CatL mRNA levels using quantitative real-time PCR (rt-PCR) in microdissected glomeruli from patients with acquired proteinuric diseases (6). Cat $L$ mRNA levels were 2-fold or greater in biopsy samples from patients with 3 types of proteinuric kidney diseases - membranous glomerulonephritis, focal segmental glomerulosclerosis, and diabetic nephropathy - compared with control samples (Figure 1A). Samples from patients with minimal change disease, which is characterized by reversible podocyte FP effacement, showed only a minor increase. There was also a signifi- 

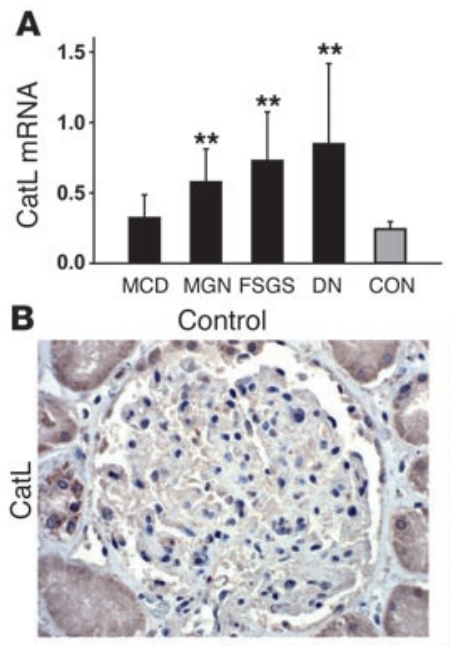

D

WT CON
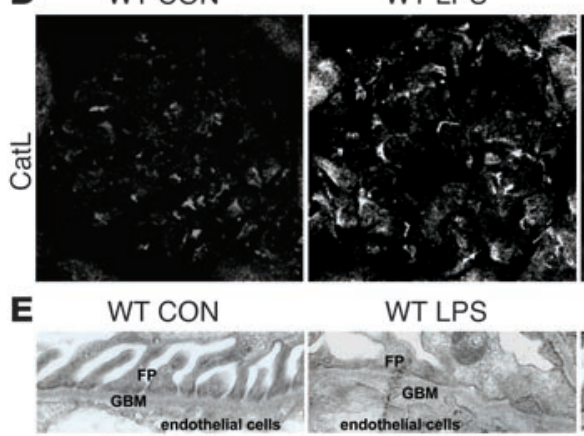

Healthy FPs

$\mathbf{F}$

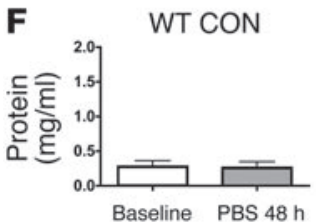

WT LPS

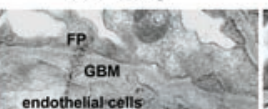

Effaced FPs
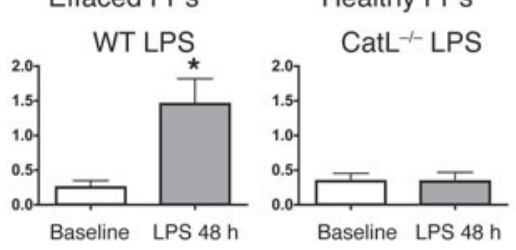

cant increase in staining for CatL in glomeruli of patients with diabetic nephropathy (in Figure 1, compare B and C). The glomerulus contains 4 major cell types: podocytes, endothelial cells, mesangial cells, and cells of the Bowman capsule. CatL was induced in the nuclei of glomerular cells, in line with its role in cleaving transcription factors (5). There was also a strong increase in CatL within cells of the Bowman capsule (Figure 1C, arrowheads) and proximal tubular cells as shown before in proteinuric states (Figure 1C, asterisk; ref. 7). Finally, CatL staining was also elevated in the cytoplasm of podocytes (Figure 1C, red arrows).

We next examined whether a similar upregulation of CatL occurs in the LPS mouse model of proteinuria (3). Immunocytochemistry using anti-CatL antibodies $(8,9)$ detected weak CatL staining in normal glomeruli (Figure 1D, left). Glomerular CatL labeling increased within 24 hours after a single LPS injection (Figure 1D, middle) but not in mice lacking CatL (Figure 1D, right) (10). LPS treatment resulted in FP effacement in control mice (Figure 1E, left and middle) but not in the LPS-treated $\mathrm{CatL}^{-/-}$mice (Figure 1E, right). Finally, urinary protein increased from a baseline level of approximately 0.25 $\mathrm{mg} / \mathrm{ml}$ to $1.2 \pm 0.15 \mathrm{mg} / \mathrm{ml}$ in control mice but remained unchanged in LPS-treated CatL $L^{-/-}$mice $(0.25 \pm 0.11 \mathrm{mg} / \mathrm{ml})$ (Figure $\left.1 \mathrm{~F}\right)$. These data provide genetic evidence that CatL is essential for proteinuria.

\section{Figure 1}

CatL is essential for proteinuric kidney diseases. (A) Quantitative rtPCR of microdissected glomeruli from human biopsies of patients with acquired proteinuric diseases: minimal change disease (MCD; $n=7$ ), membranous glomerulonephritis (MGN; $n=9$ ), focal segmental glomerulosclerosis (FSGS; $n=7$ ), and diabetic nephropathy (DN; $n=10$ ). ${ }^{\star *} P<0.01$. CON, control $(n=8)$. (B) CatL labeling of normal human kidney. (C) CatL labeling of human kidney with diabetic nephropathy, mildly reduced renal function, and nephrotic range proteinuria. (D) Immunocytochemistry of mouse glomeruli using monoclonal anti-CatL antibody. WT mice received either PBS (WT CON) or LPS (WT LPS). LPS was also injected into CatL ${ }^{--}$mice (CatL ${ }^{--}$LPS). Original magnification, $\times 400$ (C and D). (E) Electron micrographs of FPs. (F) Urinary protein levels determined using the standard Bradford protein assay. Urine was collected immediately before (Baseline) and 48 hours after addition of LPS. Each bar represents at least 8 animals.

LPS induces expression of cytoplasmic CatL. To investigate how CatL triggers proteinuria, we examined its subcellular activity before and after LPS treatment in cultured podocytes. Subcellular sites of CatL and CatB activity were visualized by a fluorogenic substrate, CV-(FR) 2, which emits light upon cleavage by CatL or CatB (3). In untreated podocytes, protease activities were restricted to lysosomes (Figure 2A, left column). LPS treatment dramatically increased protease activity, which now extended outside lysosomes into the cytoplasm (Figure 2A, middle column). The vast majority of cytoplasmic cathepsin activity after LPS administration could be attributed to CatL, since it was sensitive to the Cat $\mathrm{L}$ inhibitor Z-FF-FMK, which does not inhibit CatB (Figure 2A, right column; notice only perinuclear red staining). In line with the CatL activity in the cytoplasm, CatL protein colocalized with the lysosome-associated membrane protein LAMP-2 in lysosomes of control cells (Figure 2B, left column). After LPS treatment, there was a dramatic increase in overall CatL staining, some of which was present in the cytosol as well as in the nucleus (Figure 2B, right column). In addition, induced CatL was detected in LAMP-2-positive vesicles extending in podocyte processes close to the plasma membrane, which likely represent vesicles targeted for secretion (Supplemental Figure 1B and ref. 9). The relocalization of CatL upon LPS treatment was specific, since other lysosomal proteases such as CatB (Figure 2C) and mannosidase $\alpha$ (Supplemental Figure 1C) colocalized exclusively with LAMP-2 before and after LPS treatment. Finally, the presence of CatL in the cytoplasm was not due to lysosomal leakage (Supplemental Figure 1D).

The mRNA for CatL contains several AUG codons (Figure 2D). After translation from the first AUG, CatL is processed to yield a 30-kDa lysosomal form, called single-chain CatL (Figure 2D, black arrows). However, alternative translation initiation from a downstream AUG produces a CatL isoform devoid of the lysosomal targeting sequence (called short CatL), which localizes to the cytoplasm (Figure 2D, red arrow; ref. 5). To test whether LPS induces expression of short CatL, subcellular fractionation experiments using cultured podocytes were performed. The particulate fraction contains membranes, including lysosomes, whereas the soluble fraction represents cytoplasm. GAPDH was used as a marker for soluble cytosolic proteins and the efficiency of lysis. As expected, lysosomal single-chain CatL $(30 \mathrm{kDa})$ was present in the particulate fraction, which also contained LAMP-2, CatB, and mannosidase $\alpha$ (Figure 2E, lane 2). LPS treatment for 24 hours led to strong induction of a $34-\mathrm{kDa}$ short CatL, which was present exclusively in the 
A
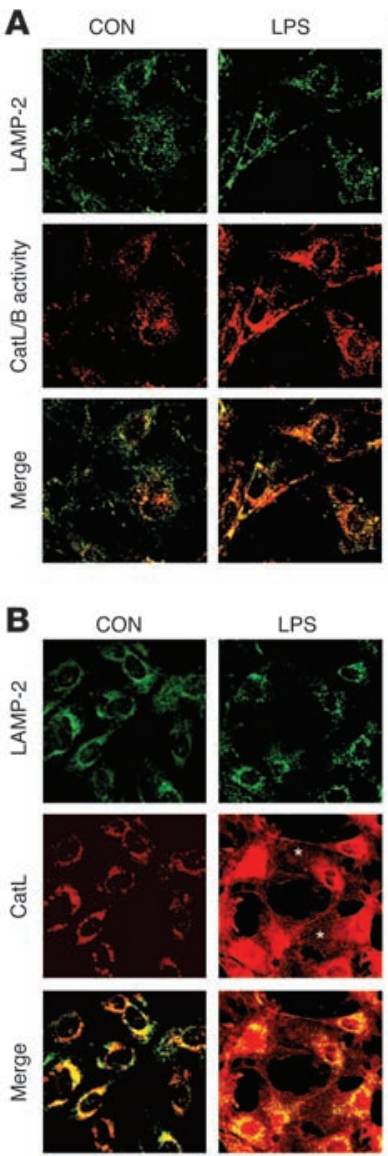

LPS + Z-FF-FMK D
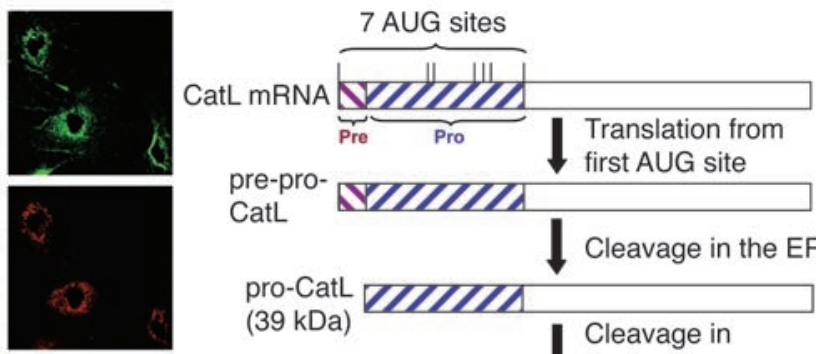

CatL

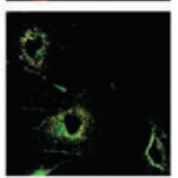

(39 kDa)
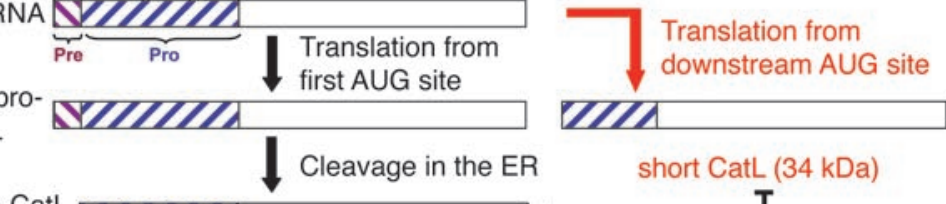

\section{R} short CatL (34 kDa)
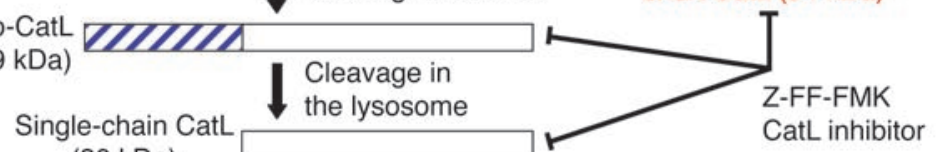
(30 kDa)

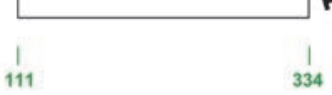

CatL inhibitor
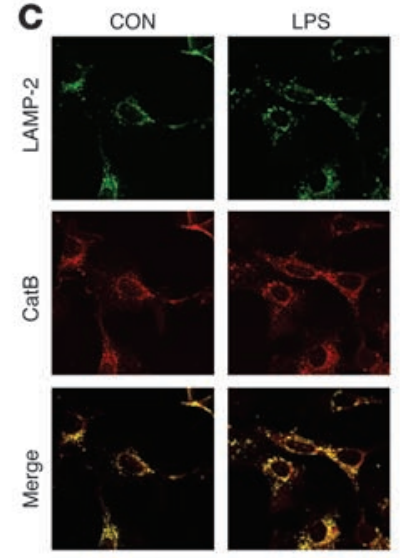

E

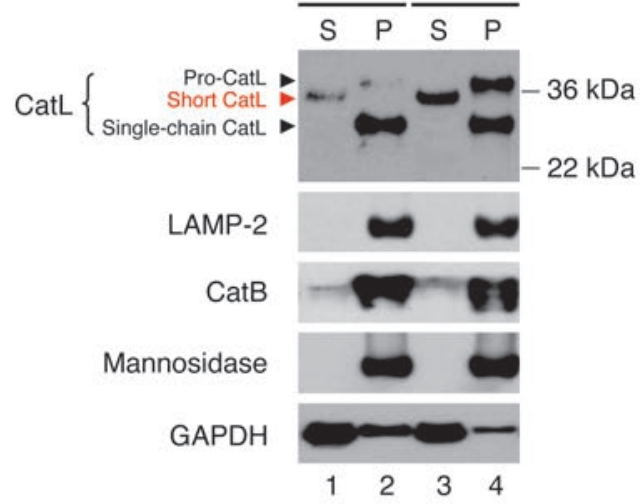

\section{Figure 2}

Induction of cytoplasmic CatL protein and activity by LPS. (A) Cultured podocytes were stained using anti-LAMP-2 antibodies and the BIOMOL CV-CatL/B activity detection kit. Control cells, cells treated with $50 \mu \mathrm{g} / \mathrm{ml}$ of LPS for 24 hours, and cells treated with LPS and $1 \mu M$ of the selective CatL inhibitor Z-FF-FMK are shown. (B) Labeling of cultured podocytes using anti-CatL antibody, untreated or after treatment with $50 \mu \mathrm{g} / \mathrm{ml}$ of LPS for 24 hours. (C) Labeling of cultured podocytes using anti-CatB antibody, untreated or after treatment with $50 \mu \mathrm{g} / \mathrm{ml}$ of LPS for 24 hours. (D) Schematic of CatL mRNA and resulting proteins. (E) Subcellular fractionation of podocytes in isotonic sucrose prior to and 24 hours after LPS treatment. Total proteins from the soluble $(S)$ and the particulate $(P)$ fractions were analyzed by Western blotting.

cytoplasm (Figure 2E, compare lanes 1 and 3). In contrast, there was no significant increase in the amount of the single-chain form, LAMP-2, or mannosidase $\alpha$ (Figure 2E, lanes 2 and 4). In addition, the soluble fractions were not contaminated with nuclear proteins such as the transcription factor Wilms tumor 1 (Supplemental Figure 1E), indicating that the soluble short form of CatL did not come from the nuclear compartment. Interestingly, addition of LPS also induced expression of the $39-\mathrm{kDa}$ pro-CatL, which is known to be secreted (Figure 2E and Supplemental Figure 1B). The ability of CatL mRNA to allow downstream AUG translation and thus generate cytoplasmic CatL was confirmed by transfecting $\mathrm{CatL}^{-/-}$fibroblasts with a cDNA in which the first AUG codon had been mutagenized (Supplemental Figure 1, F and G; ref. 5).

Loss of dynamin staining in podocytes correlates with the proteinuria and is CatL dependent. We next attempted to identify a target of cytoplasmic CatL. The computer-based algorithm PEPS (Prediction of Endopeptidase Substrates; ref. 11) identified the GTPase dynamin as a potential CatL substrate (data not shown). Dynamin is a large GTPase essential for the formation of clathrin-coated vesicles at the plasma membrane (12), and it has also been implicated in the regulation of actin dynamics in certain cell types (13). We first examined dynamin distribution in podocytes using immunogold EM. Dynamin antigenic sites were detected within the center of podocyte FPs (Figure 3A, left, asterisk) and in electron-dense areas rich in cortical actin cytoskeleton (Figure $3 \mathrm{~A}$, left, a). In addition, a high-power view localized dynamin on the cytoplasmic side of vesicular structures, which are most likely clathrin-coated pits (Figure 3A, right, v). Next, we examined dynamin staining in mice before and after LPS treatment. As expected based on the EM data, immunocytochemistry in control mice detected dynamin staining in glomeruli (Figure 3B, left), in a pattern consistent with podocyte expression. Twenty-four hours after a single LPS injection, dynamin labeling in the glomerulus appeared weaker and clustered (Figure 3B, middle panel), but it remained unchanged in tubules (data not shown). A similar dynamin staining pattern was observed in a rat model for proteinuric kidney disease in which animals are injected with puromycin aminonucleoside (PAN) (Supplemental Figure 2A; ref. 14), suggesting that changes in glomerular dynamin staining are associated with proteinuria. Importantly, dynamin staining was preserved in $\mathrm{CatL}^{-/-}$mice treated with 


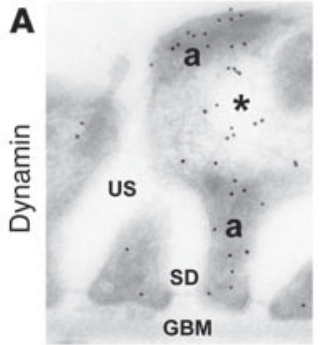

B

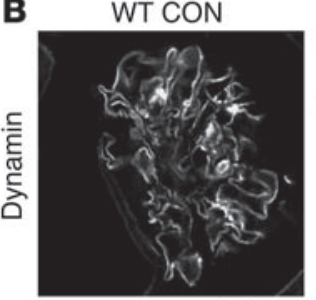

D

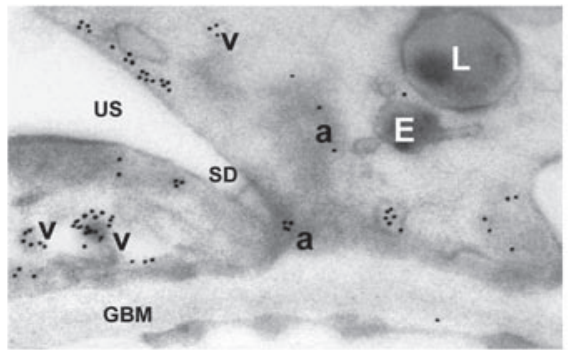

WT LPS
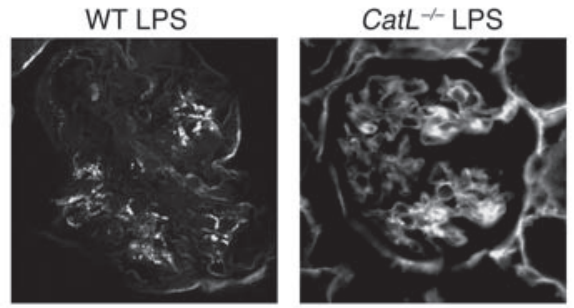

In vivo gene delivery
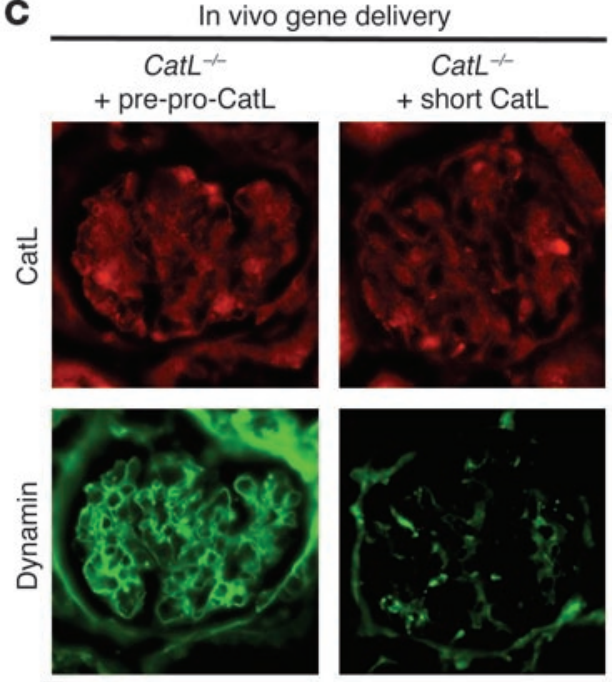

E

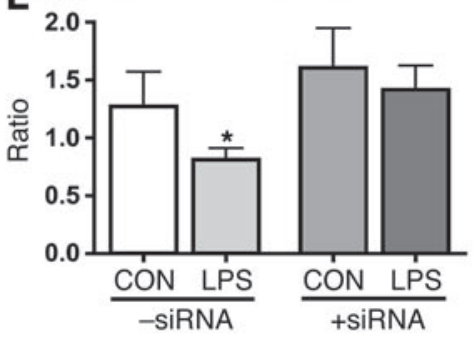

Figure 3

Altered dynamin staining in glomerulus after LPS treatment is CatL dependent. (A) Immunogold analysis of dynamin in podocyte FPs of rat glomerulus. Low-power view (left) depicts dynamin within the center of podocyte FPs (asterisk) as well as in electron-dense areas rich of cortical actin (a) (original magnification, $\times 30,000$ ). High-power view shows gold particles, which are associated with the cytoplasmic side of vesicles (v) and with electron-dense actin areas (a) (original magnification, $\times 45,000$ ). E, endosome; GBM, glomerular basement membrane; Ly, Iysosome; SD, slit diaphragm; US, urinary space. (B) Immunocytochemistry of dynamin in glomeruli of WT mice before and after injection of LPS and of CatL $L^{-/}$mice after injection of LPS. (C) Immunocytochemistry of samples from CatL ${ }^{-/-}$mice for glomerular dynamin and CatL. CatL ${ }^{-1-}$ mice had been reconstituted with either Pre-Pro-CatL (left) or with short CatL (right) using transient gene transfer. Twenty-four hours after gene transfer, glomeruli were stained using anti-CatL and anti-dynamin hudy 1 antibody. Original magnification, $\times 400$ (B and C). (D) Immunoblot of endogenous dynamin in cultured podocytes in response to LPS. Recombinant dynamin (REC), extracts of WT and Cat $L^{-/-}$podocytes, were analyzed. (E) Quantitation of dynamin in cell extracts shown in D. Dynamin signal was adjusted to actin levels.

LPS (Figure 3B, right). We hypothesize that the alteration of dynamin staining in vivo is due to proteolysis by cytoplasmic CatL. To investigate this possibility, DNAs encoding for short-form CatL or pre-pro-CatL were injected in $\mathrm{CatL}^{-/-}$mice using transient gene delivery $(15,16)$. Both DNA constructs led to glomerular CatL expression (Figure 3C, top row). Strikingly, expression of the short CatL specifically altered dynamin staining in a manner similar to that seen with LPS (Figure 3C, bottom row). Together with the fact that dynamin is a substrate of CatL in vitro (see below), these data are consistent with dynamin being cleaved by CatL in kidney after LPS treatment. Because isolated glomeruli from animals also contain other resident cells, we quantified dynamin abundance before and after LPS treatment using cultured podocytes. Western blotting of podocyte lysates revealed an approximately $30 \%$ decrease in the amount of endogenous dynamin after LPS treatment (Figure 3, D and E). Dynamin reduction was CatL dependent, since it did not occur when Cat $L$ was downregulated using siRNA (Figure 3D and Supplemental Figure 2, B and C). Together, these data suggest that the cytoplasmic CatL targets dynamin in rodent models of proteinuria.
CatL cleaves dynamin: GTP in vitro and in vivo. If dynamin is a CatL target in the cytoplasm, then recombinant dynamin should be cleavable by CatL at neutral $\mathrm{pH}$. The PEPS algorithm identified a potential recognition sequence (ELSGGA) within dynamin between amino acids 354 and 359. Interestingly, the ELSGGA motif is highly conserved among several species (Figure 4A). CatL did not cause significant cleavage of dynamin at $\mathrm{pH} 7.0$ (Figure 4C, compare lanes 1 and 2). Strikingly, addition of GTP resulted in the generation of a prominent proteolytic fragment with a molecular weight of approximately $40 \mathrm{kDa}$ (p40) (Figure 4C, lane 3). p40 is the predicted size of the $\mathrm{N}$-terminal fragment after cleavage at the ELSGGA sequence (Figure 4A). Another fragment, p55, is observed in the absence of added protease (Figure 4C, lane 1). Thus, p55 is not a precursor of $\mathrm{p} 40$. Furthermore, incubation of dynamin with CatB generated p55 in a nucleotide-independent manner (Figure 4C, lanes 5-8), whereas the protease furin was unable to cleave dynamin (Figure 4C, lanes 9-12). Thus, while p55 is produced by a number of proteases and thus represents a "hot spot" for proteolysis (17), p40 is generated by CatL only when dynamin is in the GTP-bound conformation. Interestingly, addition of 
A

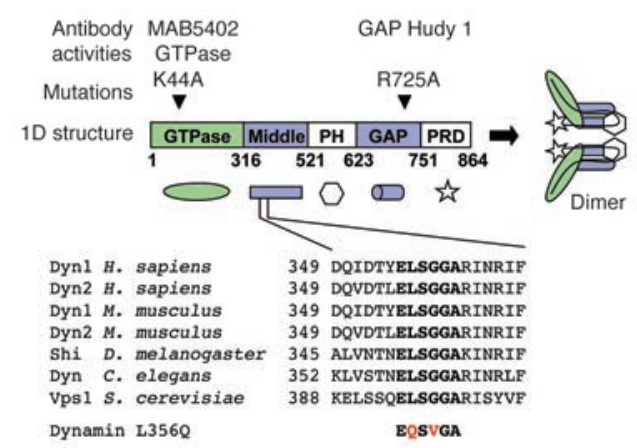

B

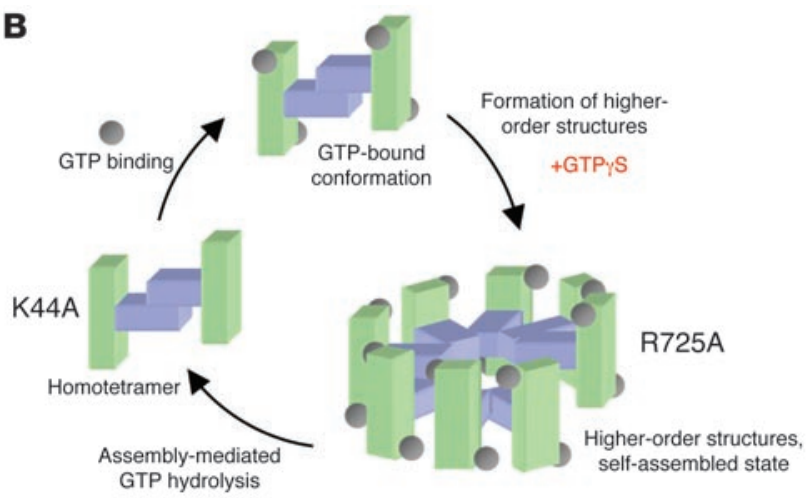

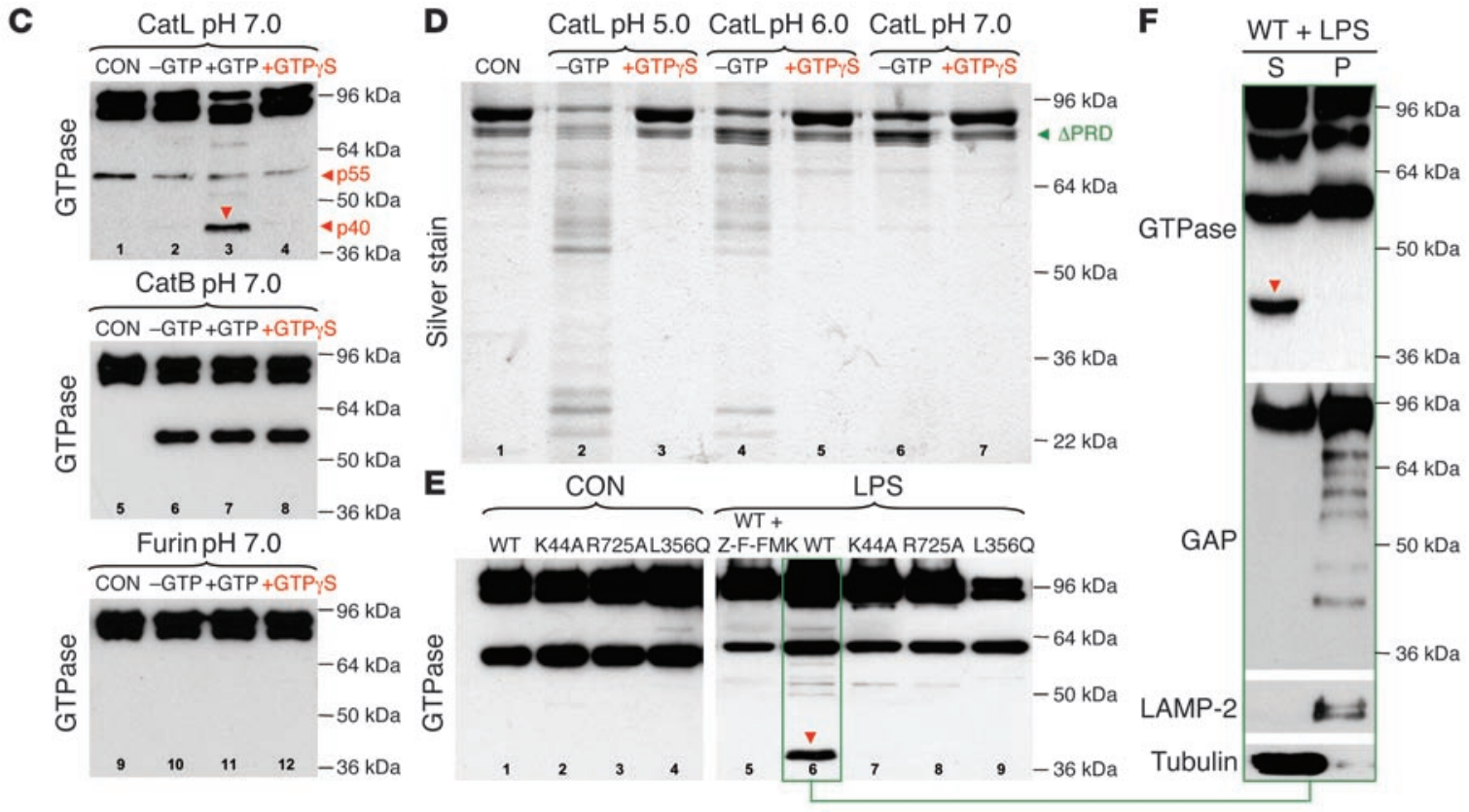

Figure 4

Effects of the nucleotide-bound and assembly state of dynamin on CatL cleavage in vitro and in vivo. (A) Domain structure of dynamin, corresponding antibodies, and amino acid sequence of predicted CatL cleavage sites. Note that the ELSGGA sequence is a highly conserved motif throughout the species. PH, pleckstrin homology domain; PRD, proline-arginine rich domain; Shi, dynamin homolog in Drosophila; Vsp1, dynamin homolog in yeast. (B) Schematic depiction of dynamin GTPase cycle. In its basal state, dynamin is a homotetramer. Self-assembly into higher-order structures such as rings or spirals can be promoted by GTPYS and activates assembly-mediated GTP hydrolysis, which in turn drives disassembly. Dynamin's middle domain is located inside the spiral. (C) Recombinant dyn1 (20 pmol) (CON) was mixed with CatL (1 pmol) (top panel), CatB (middle panel), or Furin (bottom panel). The reactions were performed at pH 7.0 under nonassembly conditions (200 mM NaCl). Where indicated, $200 \mu \mathrm{M}$ GTP or $1 \mathrm{mM}$ GTP $\mathrm{S}$ was present. Proteolytic products were detected by monoclonal anti-dynamin antibody against the GTPase domain. (D) Silver staining of recombinant dyn1 incubated with CatL at different pHs in the presence or absence of GTPYS. (E) Western blot analysis using GTPase antibody of podocyte extracts infected with various dynamin mutants before or after addition of $100 \mu \mathrm{g} / \mathrm{ml}$ LPS for 20 hours. Note the appearance of a 40-kDa fragment (arrow). When indicated, podocytes were treated with $1 \mu \mathrm{M}$ of the selective CatL inhibitor Z-FF-FMK for the duration of the LPS treatment. (F) Western blot analysis of subcellular fractionation of podocytes expressing dynWT for 24 hours after LPS treatment. Extracts were blotted using antibodies against the GTPase domain ( $N$-terminal), GAP domain (C-terminal), LAMP-2, and tubulin.

GTPYS (nonhydrolyzable GTP analog) did not stimulate cleavage by CatL (Figure 4C, lane 4). These data can be explained in terms of dynamin's oligomerization status. In its basal state, dynamin is a homotetramer that can self-associate into rings or spirals when bound to GTP (Figure 4B). These higher-order dynamin structures exhibit elevated GTPase activity, which in turn drives their disassembly. GTPYS stabilizes oligomerized dynamin due to inhibition of GTP hydrolysis (18). Dynamin oligomerization is mediated by the middle and GAP domains of dynamin (19), and based on a
cryo-EM reconstruction of assembled dynamin (20), amino acids ELSGGA (located in the middle domain) are predicted to be inaccessible when dynamin is self-assembled (Figure 4B). To test the idea that dynamin self-assembly protects against CatL cleavage, we performed additional cleavage experiments at an acidic $\mathrm{pH}$ where Cat $\mathrm{L}$ is more active. At $\mathrm{pH} 5.0$ and 6.0, CatL was highly reactive toward recombinant dynamin, even in the absence of GTP (Figure 4D, lanes 2 and 4). Strikingly, this proteolysis was inhibited by addition of GTPYS (Figure 4D, lanes 3 and 5). Together, our data 

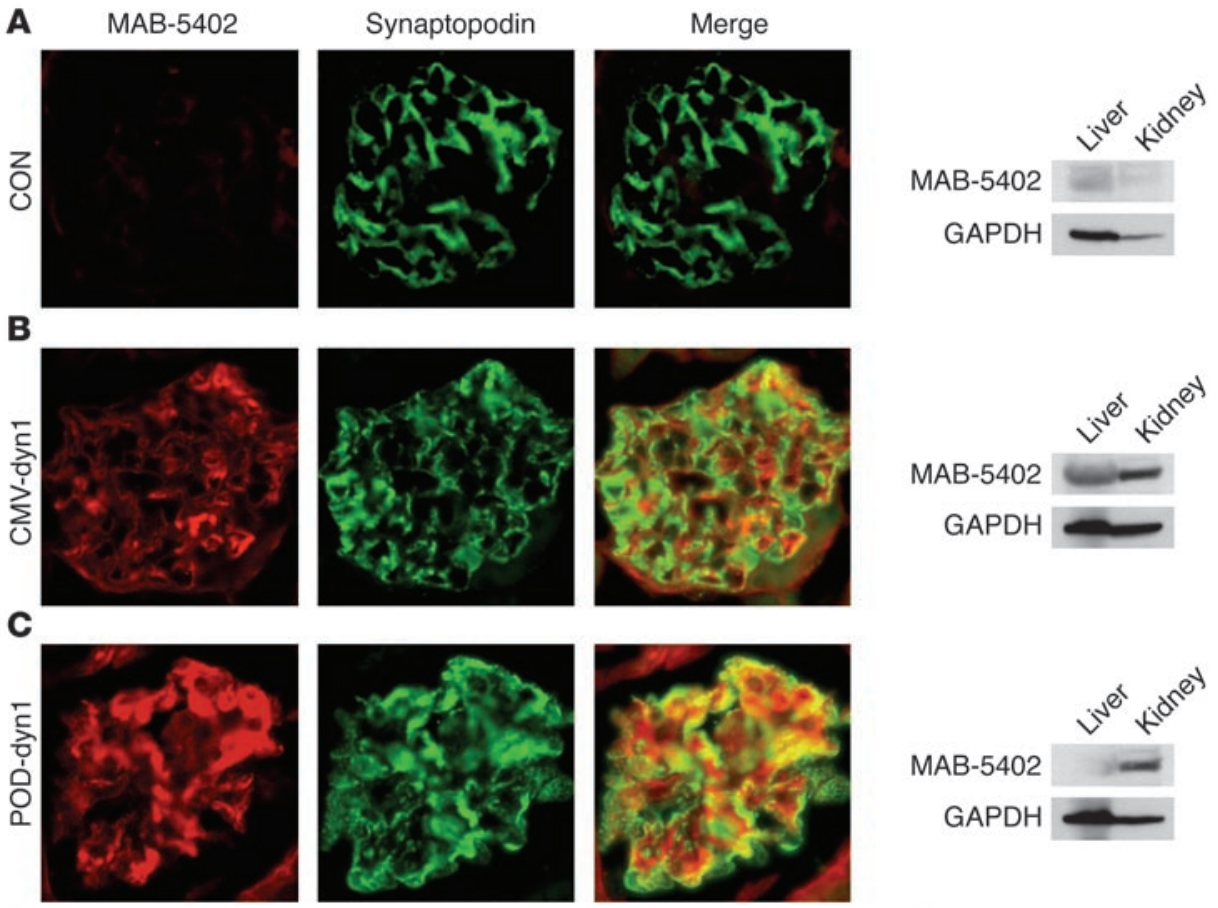

D
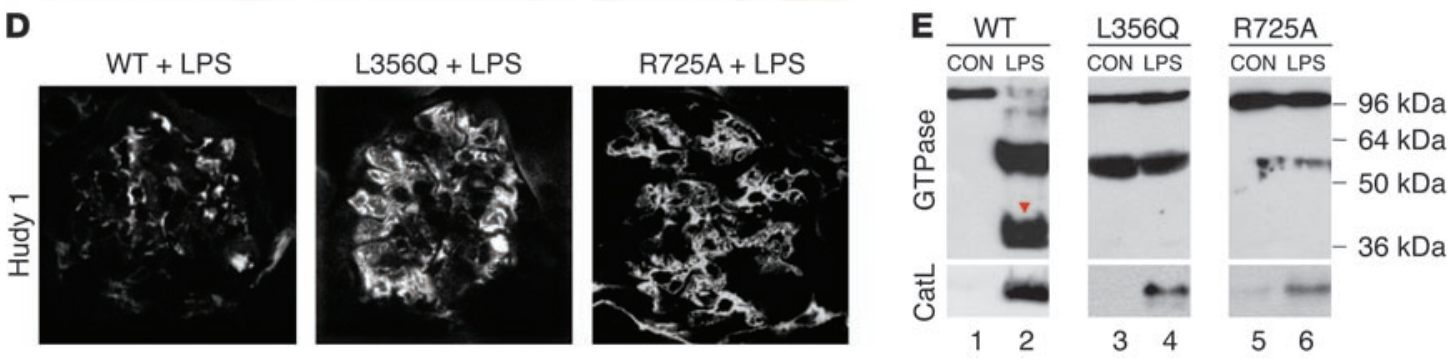

\section{Figure 5}

LPS-induced dynamin cleavage in mouse kidneys. (A-C) Double immunofluorescence of dyn1 (MAB-5402 antibody; red) and the podocyte marker synaptopodin (green). Mice were injected with podocin-driven expression vector lacking the dynamin gene (A), CMV-dyn1 expression vector (B), and POD-dyn1 expression vector (C). Western blot analysis of total kidney and liver extracts isolated from animals injected with different cDNAs as indicated in the figure. (D) Immunocytochemistry of glomeruli from mice that were injected with LPS. Twenty-four hours after LPS injections, animals received cDNA expressing dyn ${ }^{\mathrm{WT}}$, dyn ${ }^{\mathrm{L} 356 \mathrm{Q}}$, and dyn $\mathrm{n}^{\mathrm{R} 25 \mathrm{~A}}$ and were sacrificed 14 hours later. Glomeruli were stained using monoclonal anti-dynamin hudy 1 antibody. Original magnification, $\times 400$ (A-D). (E) Western blot analysis of kidney extracts after gene delivery of different dyn1 cDNAs using the GTPase and CatL antibody before and after addition of LPS.

are consistent with the hypothesis that the primary site recognized by CatL is within a domain that becomes inaccessible upon dynamin self-assembly.

To further explore CatL-mediated dynamin cleavage, we infected cultured podocytes with adenoviruses encoding different dynamin mutants (Figure 4A) and subsequently treated them with LPS. As expected, addition of LPS to cells expressing $\mathrm{dyn}^{\mathrm{WT}}{ }^{\mathrm{T}}$ resulted in generation of $\mathrm{p} 40$ (Figure 4E, lane 6), which was inhibited by the addition of the CatL inhibitor Z-FF-FMK (Figure 4E, lane 5). Importantly, LPS treatment of podocytes expressing dyn ${ }^{\mathrm{K} 44 \mathrm{~A}}$ (a mutant that cannot bind GTP) did not result in detectable levels of p40 (Figure 4E, lane 7), consistent with our data that in vitro cleavage of dynamin by CatL at neutral pH is GTP dependent. To confirm the identity of the cleavage site, we created $\mathrm{dyn}^{\mathrm{L} 356 \mathrm{Q}}$, in which the ELSGGA sequence was mutated to EQSVGA. The addition of LPS to cultured podocytes overexpressing dyn ${ }^{\mathrm{L} 356 \mathrm{Q}}$ yielded no $\mathrm{p} 40$ (Figure 4E, lane 9). Finally, we examined a GTPase-defective dynamin mutant carrying a mutation in its GAP domain $\left(\mathrm{dyn}^{\mathrm{R} 725 \mathrm{~A})}\right.$. This mutant dynamin oligomerizes, but is impaired in assembly-stimulated GTP hydrolysis (Figure 4B; ref. 19). dyn ${ }^{\mathrm{R} 725 \mathrm{~A}}$ is therefore predicted to live longer in the assembled state. Consistent with our model, LPS treatment of cells expressing $d y n^{\mathrm{R} 725 \mathrm{~A}}$ did not generate p40 (Figure 4E, lane 8). To demonstrate that dynamin cleavage by CatL occurred in the cytoplasm, we performed subcellular fractionation experiments. Thus, the $\mathrm{N}$-terminal $\mathrm{p} 40$ was detected only in the supernatant fraction (Figure 4F, left lane, GTPase), whereas the C-terminal part of dynamin was found degraded in the pellet fraction (Figure 4F, right lane, GAP). Together, these data support a model in which CatL specifically targets the GTP-bound form of dynamin in the cytoplasm by recognizing an evolutionally conserved ELSGGA motif and that dynamin self-assembly into higherorder structures such as rings or spirals prevents CatL cleavage.

To demonstrate that dynamin is cleaved by cytoplasmic CatL during proteinuric kidney disease, we looked for p40 in mouse kid- 
A
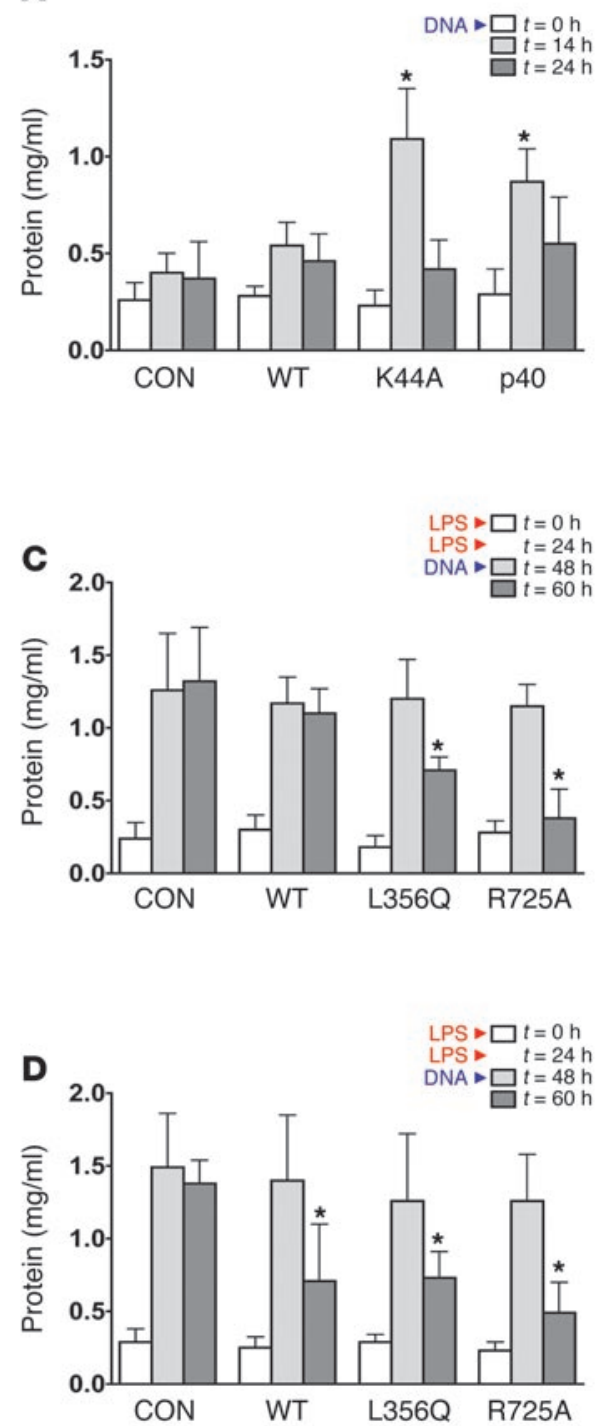

B
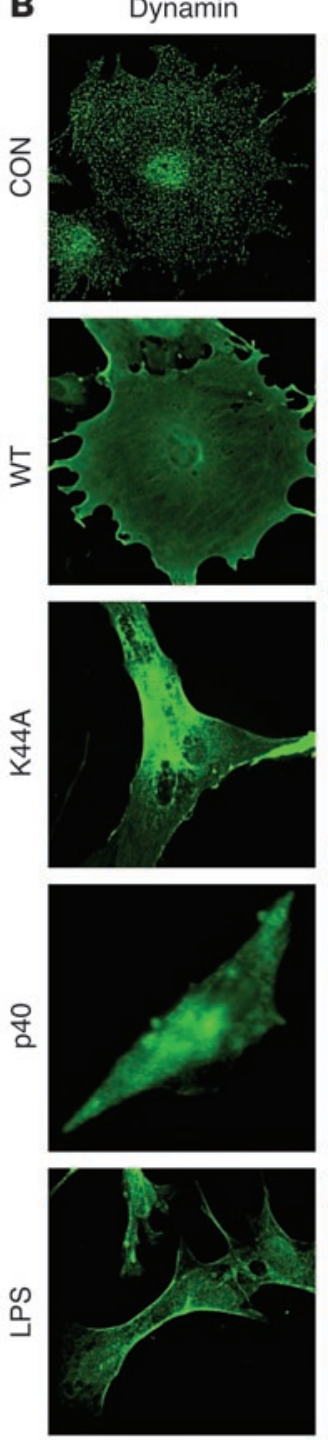

Actin
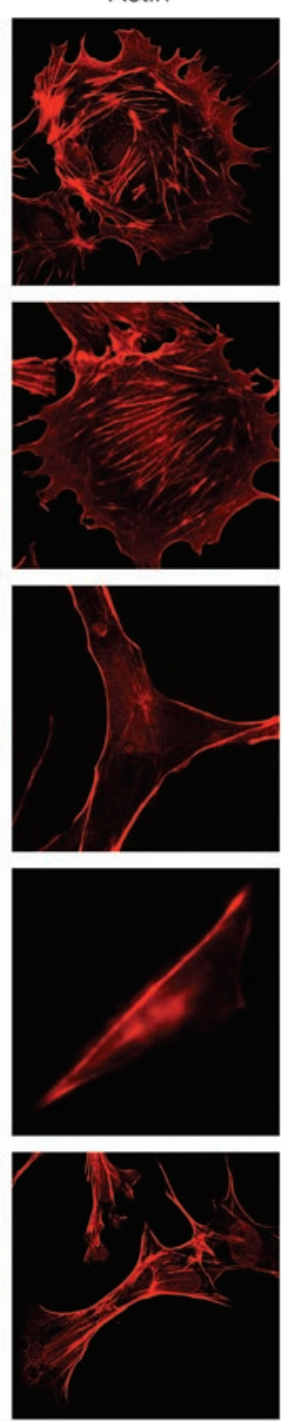

\section{Figure 6}

The effects of dynamin mutants on proteinuria and podocyte morphology. (A) Urinary protein levels determined using the standard Bradford protein assay. Urine was collected immediately before $(0 \mathrm{~h})$ and 14 and 24 hours after injection of podocin-driven expression vectors containing different dynamin constructs as indicated in the figure. Each bar represents at least 10 animals. (B) Cultured podocytes were infected with adenoviruses expressing the indicated dynamin constructs. Eighteen hours after infection, cells were stained with hudy 1 (green) to visualize dynamin and rhodamine phalloidin (red) to visualize F-actin. (C) Urinary protein levels determined using the standard Bradford protein assay. Mice were injected at 0 and 24 hours with LPS to induce proteinuria. At 48 hours (peak proteinuria), mice received empty vector, CMV-dyn ${ }^{\mathrm{WT}}$, CMV-dyn ${ }^{\mathrm{L} 356 \mathrm{Q}}$, or CMV-dyn ${ }^{\mathrm{R} 25 \mathrm{~A}}$. Urinary protein levels were determined 12 hours after injection. Each data point represents at least 10 animals. (D) Urinary protein levels determined using the standard Bradford protein assay. Mice were injected at 0 and 24 hours with LPS to induce proteinuria. At 48 hours (peak proteinuria), mice received empty vector, POD-dynWT, POD-dyn ${ }^{\mathrm{L} 356 \mathrm{Q}}$, or POD-dyn ${ }^{\text {725A }}$. Urinary protein levels were determined 12 hours after injection. Each bar represents at least 10 animals. ney extracts after LPS treatment. Since the GTPase antibody, which recognizes $\mathrm{p} 40$, was not sufficiently sensitive to detect endogenous dynamin cleavage fragments (data not shown), we used a genedelivery protocol to express dynamin in mouse kidneys $(15,16)$. We delivered dyn 1 because overexpression of dyn 2 sometimes induces apoptosis (21). rt-PCR showed that podocytes normally express dyn2 (ubiquitous form) and some dyn3 (predominantly expressed in testis), but no dyn1 (neuronal isoform; Supplemental Figure 3A). Dyn 1 was expressed from a CMV promoter (CMV-dyn) or from the podocyte-specific podocin promoter (POD-dyn; ref. 22). Genedelivered dyn 1 was distinguished from endogenous dyn 2 using the monoclonal dynamin antibody MAB-5402, which predominantly recognizes dyn 1 (Supplemental Figure 3B). As expected, MAB-5402 weakly stained control glomeruli (Figure 5A), whereas it strongly stained glomeruli 14 hours after delivery of CMV-dyn 1 (Figure 5B) or POD-dyn 1 (Figure 5C). The CMV promoter directed expression of dyn 1 in the liver and kidney (Figure 5B, Western blot), and dyn 1 was detected in virtually all resident cell types of the glomerulus including podocytes, as seen from colocalization with synaptopodin (Figure 5B, Merge). In contrast, the podocin promoter directed expression exclusively in the kidney (Figure 5C, Western blot), and dyn 1 localized predominantly in podocytes (Figure 5C, Merge). The presence of dyn 1 in FPs of podocytes was demonstrated using EM (Supplemental Figure 3C). Importantly, LPS treatment led to altered staining of gene-delivered dyn $1{ }^{\mathrm{WT}}$ in glomeruli, whereas the staining of $d y n^{\mathrm{L} 356 \mathrm{Q}}$ and $d y n^{\mathrm{R} 725 \mathrm{~A}}$ remained unchanged (Figure $5 \mathrm{D}$ ). Moreover, LPS treatment resulted in generation of p40, but only in mice expressing dyn ${ }^{\mathrm{WT}}$ (Figure 5E, lane 2) and not in mice expressing $\mathrm{dyn}^{\mathrm{L} 356 \mathrm{Q}}$ and $\mathrm{dyn}^{\mathrm{R} 725 \mathrm{~A}}$ (Figure $5 \mathrm{E}$, lanes 4 and 6). Generation of $\mathrm{p} 40$ required the presence of CatL, since it was not detected in $\mathrm{CatL}^{-/-}$ mice injected with LPS (Supplemental Figure 3D). Western blotting also detected a dynamin fragment of approximately $55 \mathrm{kDa}$. As in cultured podocytes, the presence of this fragment was LPS and CatL independent (Figure 5E, lanes 3 and 5, and Supplemental Figure 3D), supporting the idea that it is generated by other proteases during extract preparation. These experiments extend our observations in the cultured podocytes and indicate that LPS induces CatL-dependent cleavage in live mice.

Dynamin is required for normal glomerular function. The hypothesis that cleavage of dynamin by CatL leads to proteinuria implies that 
dynamin is essential for podocyte morphology in healthy kidneys. In support of this notion, expression of dominant-negative $\mathrm{dyn}^{\mathrm{K} 44 \mathrm{~A}}$ in mouse podocytes caused severe proteinuria (Figure $6 \mathrm{~A}$ and Supplemental Table 1) and FP effacement (Supplemental Figure 4B, 14 hours). Proteinuria and FP effacement were maximum 14 hours after gene delivery and returned to baseline after loss of dyn ${ }^{\mathrm{K} 44 \mathrm{~A}}$ expression (Supplemental Figure 4, A and B, and data not shown). Expression of dyn ${ }^{\mathrm{WT}}$ did not cause changes in FP architecture (data not shown) or significant proteinuria (Figure 6A and Supplemental Table 1), demonstrating specificity of the dyn ${ }^{\mathrm{K} 44 \mathrm{~A}}$ phenotype. Importantly, expression of $\mathrm{p} 40$ also caused proteinuria (Figure 6A and Supplemental Table 1), demonstrating that this dynamin fragment has dominant-negative characteristics with respect to podocyte function.

Since podocyte FP effacement is primarily driven by the rearrangement of the actin cytoskeleton (23), we examined actin morphology in cultured podocytes expressing dyn ${ }^{\mathrm{K} 44 \mathrm{~A}}$ and $\mathrm{p} 40$. Podocytes were infected using an adenoviral expression system, which allows greater than $90 \%$ infection efficiency (24). The experiments were performed using the neuronal isoform of dyn 1 (Figure 6B) as well as the ubiquitously expressed dyn2 (Supplemental Figure 5). The 2 isoforms yielded identical results, demonstrating that the observed phenotypes in podocytes were not isoform specific (compare F-actin staining in cells expressing dyn ${ }^{\mathrm{WT}}$ and dyn ${ }^{\mathrm{K} 44 \mathrm{~A}}$ in Figure 6B and Supplemental Figure 5). Podocyte actin is organized in parallel bundles of stress fibers and a cortical ring of filamentous actin (Figure 6B, CON). Expression of dyn ${ }^{\mathrm{WT}}$ did not significantly alter the F-actin staining pattern (Figure 6B, WT). In contrast, the expression of $d y n^{\mathrm{K} 44 \mathrm{~A}}$ or $\mathrm{p} 40$ abolished stress fibers while enhancing the cortical actin web, resulting in a polygonal cellular shape (Figure 6B). Similar actin and cell morphology phenotypes were associated with LPS (Figure 6B) and PAN treatments (25). Thus, occurrence of proteinuria in mice expressing dyn ${ }^{\mathrm{K} 44 \mathrm{~A}}$ or $\mathrm{p} 40$ (Figure $6 \mathrm{~A}$ ) correlates with changes in podocyte morphology due to changes in actin cytoskeleton (Figure 6B).

If dynamin is a target of Cat $\mathrm{L}$, then $\mathrm{dyn}^{\mathrm{L} 356 \mathrm{Q}}$ and $\mathrm{dyn}^{\mathrm{R} 725 \mathrm{~A}}$, which are resistant to CatL cleavage, might be beneficial during LPS-induced proteinuria. At peak proteinuria (48 hours after initial LPS), mice were injected with empty vector, dyn ${ }^{\mathrm{WT}}$, dyn ${ }^{\mathrm{L} 356 \mathrm{Q}}$, or dyn ${ }^{\mathrm{R} 725 \mathrm{~A}}$ either from the CMV promoter (Figure 6C) or the podocin promoter (Figure $6 \mathrm{D})$, and the degree of proteinuria was analyzed 12 hours after DNA injection. Strikingly, expression of dyn ${ }^{\mathrm{R} 725 \mathrm{~A}}$ led to almost complete resolution of proteinuria, whereas expression of dyn ${ }^{\mathrm{L} 356 \mathrm{Q}}$ reduced proteinuria by approximately $50 \%$ (Figure 6, C and D; 60-hour time point). Interestingly, while $\mathrm{CMV}-\mathrm{dyn}{ }^{\mathrm{WT}}$ had no affect on proteinuria (Figure 6C), podocin-driven expression reduced proteinuria by $50 \%$ (Figure 6D). The ability of POD-dyn ${ }^{\mathrm{WT}}$ to overcome proteinuria is likely due to the higher level of podocyte-specific dynamin expression expected from the podocin promoter. Indeed, kidney extracts from animals expressing POD-dyn ${ }^{\mathrm{WT}}$ contained the same level of dynamin as extracts from animals expressing CMV-dyn ${ }^{\mathrm{WT}}$, even though the latter was expressed in all cell types in the glomerulus (Figure 5, B and C). Thus, while expression of a high level of dyn ${ }^{\mathrm{WT}}$ can partially reverse LPS-induced FP effacement, dyn ${ }^{\mathrm{L} 356 \mathrm{Q}}$ and $\mathrm{dyn}^{\mathrm{R} 725 \mathrm{~A}}$ are more potent. Interestingly, dyn ${ }^{\mathrm{R} 725 \mathrm{~A}}$ is the most powerful, most likely due to restoration of optimal cellular levels of dynamin:GTP.

\section{Discussion}

In this study, we investigated the role of the protease CatL and the large GTPase dynamin in healthy and diseased kidney podocytes.
We show that dynamin is normally required to maintain the ultrafiltration barrier in kidneys, possibly via regulation of the actin cytoskeleton in podocytes. Using a mouse model for inducible kidney failure, we found that cleavage of dynamin by a cytoplasmic form of CatL leads to podocyte failure and proteinuria. Gene delivery of CatL-resistant dynamin mutants can prevent and even reverse proteinuria. Our data define a new role for cytoplasmic CatL (trigger) and dynamin (target) in the pathogenesis of glomerular proteinuria and open new potential avenues for pharmacological intervention of kidney disease.

Previous inhibitor studies suggested that CatL is involved in proteinuric kidney disease (4), and our current (Figure 1D) and previous work (3) has shown that CatL is upregulated in rodent models for nephropathy. Consistent with these findings, we observed an increase in levels of glomerular CatL mRNA in a number of human proteinuric diseases (Figure 1A) that correlated with a dramatic increase in the protein level in glomeruli (Figure 1C). Using knockout mice, we provide definitive evidence that CatL is essential to cause nephropathy in response to LPS in a mouse model (Figure 1, D-F). Furthermore, we have shown that after LPS treatment, CatL appears in the cytoplasm, due to expression of the short form of the protein. Together, the data indicate that localization of CatL to the cytoplasm represents a key event in the induction of glomerular kidney disease. Consistent with this model, we show that dynamin, a cytoplasmic protein, is essential for kidney function and that it is cleaved by CatL after LPS treatment. Importantly, the dynamin p40 fragment generated by CatL cleavage functions as a dominant-negative inducer of proteinuria. Thus, the activity of the cytoplasmic CatL, in contrast to its lysosomal counterpart, seems to be specific and to yield a functional product ( $\mathrm{p} 40)$. These data argue that complete destruction of dynamin is not necessarily required to cause kidney failure.

Intriguingly, the CatL cleavage site is highly conserved among dynamin family members (Figure 4A), and its accessibility is suppressed by dynamin oligomerization. Moreover, cytoplasmic CatL targets only the GTP-bound form of dynamin, implying that only a portion of dynamin is cleaved in vivo. Our previous experiments indicate that dynamin:GTP is the active form of the enzyme (19, 26), so it is tempting to speculate that CatL functions to switch off dynamin much like the result of dynamin self-assembly. It remains to be seen whether this novel switch-off mechanism is ever used during normal cell physiology.

EM revealed 2 populations of actin in FPs of podocytes; one is the actin bundle running above the level of slit diaphragms, and the other is the cortical actin network located beneath the plasmalemma (27). Our data show that dynamin colocalizes with both of these populations (Figure 3B). It appears that FPs have the molecular makeup for constant morphological rearrangement in order to accommodate glomerular filtration. This membrane reshaping is most likely driven by rapid changes in the actin network (28), and our study suggests that it requires functional dynamin. On its $\mathrm{C}$ terminus, dynamin contains a proline-arginine rich domain (PRD) that binds directly to the Src homology 3 (SH3) domains of multiple proteins, some of which are actin-regulating or -binding proteins including profilin, Nck, Grb2, syndapin, intersectin, cortactin, $\mathrm{mABP} 1$, and tuba (reviewed in ref. 13). It is through these interactions that dynamin is thought to coordinate membrane remodeling and actin filament dynamics during endocytosis, cell morphogenesis, and cell migration. Despite these links between dynamin and actin, it is still unclear how exactly dynamin regulates 
actin dynamics. Our results identify podocytes, with their complex actin dynamics, as an appropriate cell type for investigating the interplay between dynamin's role in endocytosis and its ability to regulate the actin cytoskeleton. Indeed, formation of a cortical actin cytoskeleton in cells expressing $\mathrm{dyn}^{\mathrm{K} 44 \mathrm{~A}}$ or $\mathrm{p} 40$ or that have been treated with LPS (Figure 6B) could result from the inhibition of endocytosis, misregulation of actin dynamics, or both. While at present we have no direct evidence for a direct connection between actin and dynamin, addition of LPS does not inhibit endocytosis in cultured podocytes (Supplemental Figure 6), suggesting that loss of endocytosis per se is not sufficient to generate a cortical actin network. In agreement with this conclusion are experiments showing that expression of a known endocytosis inhibitor, dominant-negative auxilin ${ }^{\mathrm{H} 875 \mathrm{Q}}(29)$, impaired endocytosis to the same extend as dyn ${ }^{\mathrm{K} 44 \mathrm{~A}}$ (Supplemental Figure 6A), yet it did not alter actin morphology (Supplemental Figure 6B). In addition, nondifferentiated podocytes contained predominantly cortical actin (Supplemental Figure 6B), yet they exhibited WT levels of endocytosis (Supplemental Figure 6A). In sum, there seems to be no correlation between levels of endocytosis and actin dynamics in podocytes, raising the possibility that dynamin mutants might primarily act on podocyte actin dynamics. This conclusion is also in line with the observation that CatL reduced endogenous dynamin by only $30 \%$ (Figure 3D), possibly maintaining dynamin's role in endocytosis. Regardless of these observations, dynamin is clearly present on clathrin-coated pits in podocytes (Figure 3A), and changes in endocytosis have been implicated in some forms of podocyte failure (30). Clearly, more work is needed to define the exact role(s) of dynamin in podocytes.

Proteinuria was resolved by expression of $\mathrm{dyn}^{\mathrm{R} 725 \mathrm{~A}}, \mathrm{dyn} \mathrm{n}^{\mathrm{L} 356 \mathrm{Q}}$, and to some degree dyn ${ }^{\mathrm{WT}}$. While our study shows that dynamin is efficiently delivered and expressed in podocytes, it is unlikely that every podocyte received dynamin. We propose that damaged podocytes may be particularly amenable to uptake of DNA presented in polymers $(8,31)$. Alternatively, it is conceivable that the effects of gene-delivered dynamin has multiple effects in podocytes. For example, it seems possible that restoration of podocyte actin has a salutary effect on the slit diaphragm function. Finally, gene-delivered dynamin in podocytes may have a non-cell-autonomous effect on other resident glomerular cells such as glomerular endothelial cells. Whatever the precise mechanism, the use of dynamin mutants as a treatment for human kidney disease is an attractive subject for future experiments.

\section{Methods}

Cells, antibodies, reagents, and standard techniques. Mouse podocyte cell lines were grown as described previously (32). Dynamin antibodies included anti-dynamin (hudy 1) from Upstate Technology; mouse anti-dyn1 5402 from Chemicon; VAM-SV041 from Stressgen. Two rabbit antisera against CatL were used as described previously $(8,33)$. Cat $\mathrm{L}^{-/}$fibroblasts were maintained as described previously (34). Stable CatL-knockdown cell lines were generated with a vector-based siRNA directed against CatL (target sequence 5'-GTGGACTGTTCTCACGCT-3'). Quantitative PCR was performed on an Applied Biosystems 7300 Real-Time PCR System. Fold expression changes were calculated using the comparative $C_{T}$ method for relative quantitation with the equation $2^{-\Delta \Delta C T}$. Protein expression levels for dynamin and CatL were calculated using results of densitometric analysis from 7 independent experiments with Kodak 1D Image Analysis software. Statistical significance was assessed with the unpaired Student's $t$ test with Welch's correction. $P$ less than 0.05 was considered statistically significant.
Transfections with CatL constructs were performed using Lipofectamine 2000 (Invitrogen). Immunocytochemical analysis of cultured podocytes was performed as described previously (3). BIOMOL CV-CatL/B activity kit was utilized as described in the manufacturer's instructions. The fluorophore cresyl violet $\left[\mathrm{CV}-(\mathrm{FR})_{2}\right]$ substrate becomes florescent after CatL/B cleavage of the attached Phe-Arg groups. This substrate easily penetrates the cell membrane and the membranes of the internal cellular organelles, enabling the detection of cathepsin activity within living podocytes. Immunoperoxidase labeling of human tissue was done on formalin-fixed kidney biopsy samples embedded in paraffin. Transmission electron microscopy and immunoelectron microscopy were performed as described previously (35). Subcellular fractionation was performed as described (36).

Animals and treatments. All animal studies were approved by the MGH Subcommittee for Research Animal Care. C57BL/6 mice were obtained from The Jackson Laboratory. Cat $L^{-/-}$mice were on a pure $\mathrm{C} 57 \mathrm{BL} / 6$ background (10). The mouse model LPS-induced proteinuria was utilized as previously described (3). The rat PAN nephrosis model was induced as described (37).

Patients and quantitative glomerular rt-PCR. Microdissected glomeruli from patients with proteinuric diseases and from control subjects were analyzed. Biopsies were obtained from patients and donors after informed consent and with approval of the local ethical committees. For control biopsies, renal tissue was derived from pretransplantation kidney biopsies during cold ischemia time from 7 living and 1 cadaveric donor $(n=8)(38)$. Statisti$\mathrm{cal}$ analysis was performed using the Kruskal-Wallis test and Mann-Whitney $U$ test. $P$ less than 0.05 was considered statistically significant.

Processing of dynamin by CatL in vitro. Recombinant dynamin was purified as described previously (39). One microgram of dynamin (10 pmol) was diluted in buffer containing $200 \mathrm{mM} \mathrm{NaCl}, 10 \mathrm{mM}$ HEPES pH 7.0, $2 \mathrm{mM}$ EGTA, $1 \mathrm{mM} \mathrm{MgCl}_{2}$, and $1 \mathrm{mM}$ DTT. When indicated, $200 \mu \mathrm{M}$ of GTP or $1 \mathrm{mM}$ of GTPYS was added, and dynamin was allowed to bind nucleotides for 10 minutes on ice. The reaction was initiated by addition of $0.5 \mu$ l of purified CatL (specific activity $4.13 \mathrm{U} / \mathrm{mg}$ of protein from Sigma-Aldrich), and samples were placed at $37^{\circ} \mathrm{C}$ in the water bath for 10 minutes. Total assay volume was $20 \mu$ l. The reaction was terminated with addition of E-64d inhibitor (Sigma-Aldrich) and sample buffer. For Western blot analysis, $5 \mu$ l of the samples was run on $10 \%$ SDS-PAGE. When CatB (specific activity $3.00 \mathrm{U} / \mathrm{mg}$ of protein from Sigma-Aldrich) or recombinant human furin (from R\&D Systems) were used, $2 \mu$ l of the enzymes were added in the assay.

Adenoviral infections of cultured podocytes. Podocytes were grown to $70 \%$ confluency. Cells were washed twice with $1 \times$ PBS and infected with $1.2 \mathrm{ml}$ of serum-free DMEM medium containing $100 \mu \mathrm{l}$ transactivator virus and $100 \mu \mathrm{l}$ virus expressing dyn 1 or dyn 2 . After 2 hours of infection at $37^{\circ} \mathrm{C}$, medium containing virus was replaced with full DMEM. If cells were treated with LPS or PAN, $50 \mu \mathrm{g} / \mathrm{ml}$ of LPS or $50 \mu \mathrm{g} / \mathrm{ml}$ PAN was added at this point. Eighteen to 24 hours after infection, cells were detached using trypsin and either processed for subcellular fractionation or tested in the motility assays as described in ref. 3. When indicated, $20 \mu \mathrm{M}$ of Z-FF-FMK CatL specific inhibitor (Calbiochem) was added simultaneously with LPS. Kidney extracts. Four mouse kidneys were homogenized in buffer containing $20 \mathrm{mM}$ HEPES pH 7.5, $100 \mathrm{mM} \mathrm{NaCl}, 1 \mathrm{mM} \mathrm{MgCl}$, 1 mM PMSF, proteinase inhibitors, calpain inhibitor (Calbiochem), and E-64d using Dounce homogenizer. Subsequently, cytosol was centrifuged for $10 \mathrm{~min}$ utes at $4,600 \mathrm{~g}$. Proteins were solubilized by $1 \%$ Triton X, 1 hour at $4{ }^{\circ} \mathrm{C}$, before it was spun at 70,000 $\mathrm{g}$ for 1 hour.

In vivo gene delivery. CatL plasmids encoding short and long CatL (5), dyn 1 plasmids (all pcDNA), or p2.5 podocin-promoter driven (22) were introduced into mice ( $n>10$, each construct) using the Trans IT in vivo gene delivery system according to the manufacturer's instructions (Mirus). Proteinuria was assessed using Multistix 8 SG strips (Bayer) (data not shown) and the Bradford protein assay (Sigma-Aldrich). 


\section{Acknowledgments}

This work was supported by the American Society for Nephrology (to S. Sever and J. Reiser) and the NIH (R01 DK64787 to S. Sever and R01 DK073495 to J. Reiser). J. Reiser was also supported by the KMD foundation. M.M. Altintas was supported by an NIH training grant and T32DK007540, and C.C. Möller by a Deutscher Akademischer Austausch Dienst (DAAD) Predoctoral Scholarship. The authors are grateful for the analysis of CatL cleavage sites by Thomas Reinheckel and Tobias Lohmueller, University of Freiburg. The authors are indebted to Johannes Walter for critically reading the manuscript. The fluorescence and electron microscopy work was performed in the Microscopy Core facility of the MGH Program in Membrane Biology, supported by an NIH Program Project grant (DK38452), the NIH Boston Area Diabetes and Endocrinology Research Center (DK57521), and the NIH Center for the Study of Inflammatory Bowel Disease (DK43341). We thank all members of the European Renal cDNA Bank and their patients for their support (for participating centers at the time of the study see ref. 38).

Received for publication March 5, 2007, and accepted in revised form May 9, 2007.

Address correspondence to: Sanja Sever or Jochen Reiser, Department of Medicine, Nephrology Division and Program in Glomerular Disease, MGH and Harvard Medical School, MGH-East, CNY-149, 13th Street, Boston, Massachusetts 02129, USA. Phone: (617) 724-8922; Fax: (617) 726-5669; E-mail: ssever@partners.org (S. Sever). Phone: (617) 726-9363; Fax: (617) 726-5669; jreiser@ partners.org (J. Reiser).

Mehmet M. Altintas, Sharif R. Nankoe, and Clemens C. Möller contributed equally to this work.
1. Zandi-Nejad, K., Eddy, A.A., Glassock, R.J., and Brenner, B.M. 2004. Why is proteinuria an ominous biomarker of progressive kidney disease? Kidney Int. Suppl. 66:S76-S89.

2. Tryggvason, K., Patrakka, J., and Wartiovaara, J. 2006. Hereditary proteinuria syndromes and mechanisms of proteinuria. N. Engl. J. Med. 354:1387-1401.

3. Reiser, J., et al. 2004. Podocyte migration during nephrotic syndrome requires a coordinated interplay between cathepsin 1 and alpha3 integrin. J. Biol. Chem. 279:34827-34832.

4. Baricos, W.H., O'Connor, S.E., Cortez, S.L., Wu, L.T., and Shah, S.V. 1988. The cysteine proteinase inhibitor, E-64, reduces proteinuria in an experimental model of glomerulonephritis. Biochem. Biophys. Res. Commun. 155:1318-1323.

5. Goulet, B., et al. 2004. A cathepsin L isoform that is devoid of a signal peptide localizes to the nucleus in S phase and processes the CDP/Cux transcription factor. Mol. Cell. 14:207-219.

6. Cohen, C.D., and Kretzler, M. 2003. Gene-expression analysis of microdissected renal biopsies. Methods Mol. Med. 86:285-293.

7. Olbricht, C.J., Cannon, J.K., and Tisher, C.C. 1987. Cathepsin B and L in nephron segments of rats with puromycin aminonucleoside nephrosis. Kidney Int. 32:354-361.

8. Ahn, K., et al. 2002. An alternate targeting pathway for procathepsin $\mathrm{L}$ in mouse fibroblasts. Traffic. 3:147-159.

9. Asanuma, K., Shirato, I., Ishidoh, K., Kominami, E., and Tomino, Y. 2002. Selective modulation of the secretion of proteinases and their inhibitors by growth factors in cultured differentiated podocytes. Kidney Int. 62:822-831.

10. Nakagawa, T., et al. 1998. Cathepsin L: critical role in Ii degradation and CD4 T cell selection in the thymus. Science. 280:450-453.

11. Lohmuller, T., et al. 2003. Toward computer-based cleavage site prediction of cysteine endopeptidases. Biol. Chem. 384:899-909.

12. Kirchhausen, T. 2000. Three ways to make a vesicle. Nat. Rev. Mol. Cell Biol. 1:187-198.

13. Schafer, D.A. 2004. Regulating actin dynamics at membranes: a focus on dynamin. Traffic. 5:463-469.

14. Inokuchi, S., et al. 1996. Re-evaluation of foot pro- cess effacement in acute puromycin aminonucleoside nephrosis. Kidney Int. 50:1278-1287.

15. Mayer, G., Boileau, G., and Bendayan, M. 2003. Furin interacts with proMT1-MMP and integrin alphaV at specialized domains of renal cell plasma membrane. J. Cell Sci. 116:1763-1773.

16. Moller, C.C., et al. 2007. Induction of TRPC6 channel in acquired forms of proteinuric kidney disease. J. Am. Soc. Nephrol. 18:29-36.

17. Muhlberg, A.B., Warnock, D.E., and Schmid, S.L. 1997. Domain structure and intramolecular regulation of dynamin GTPase. EMBO J. 16:6676-6683.

18. Akagi, Y., et al. 1997. Transcriptional activation of a hybrid promoter composed of cytomegalovirus enhancer and beta-actin/beta-globin gene in glomerular epithelial cells in vivo. Kidney Int. 51:1265-1269.

19. Sever, S., Muhlberg, A.B., and Schmid, S.L. 1999. Impairment of dynamin's GAP domain stimulates receptor-mediated endocytosis. Nature. 398:481-486.

20. Zhang, P., and Hinshaw, J.E. 2001. Three-dimensional reconstruction of dynamin in the constricted state. Nat. Cell Biol. 3:922-926.

21. Fish, K.N., Schmid, S.L., and Damke, H. 2000. Evidence that dynamin-2 functions as signal-transducing GTPase. J. Cell Biol. 150:145-154.

22. Moeller, M.J., Sanden, S.K., Soofi, A., Wiggins, R.C., and Holzman, L.B. 2003. Podocyte-specific expression of cre recombinase in transgenic mice. Genesis. 35:39-42.

23. Verma, R., et al. 2006. Nephrin ectodomain engagement results in Src kinase activation, nephrin phosphorylation, Nck recruitment, and actin polymerization. J. Clin. Invest. 116:1346-1359. doi:10.1172/JCI27414.

24. Damke, H., Freundlieb, S., Gossen, M., Bujard, H., and Schmid, S.L. 1995. Tightly regulated and inducible expression of a dominant interfering dynamin mutant in stably transformed HeLa cells. Methods Enzym. 257:209-221.

25. Reiser, J., et al. 2000. Regulation of mouse podocyte process dynamics by protein tyrosine phosphatases. Kidney Int. 57:2035-2042.

26. Sever, S., Damke, H., and Schmid, S.L. 2000. Dynamin:GTP controls the formation of constricted coated pits, the rate limiting step in clathrin-mediated endocytosis. J. Cell Biol. 150:1137-1148.
27. Ichimura, K., Kurihara, H., and Sakai, T. 2003. Actin filament organization of foot processes in rat podocytes. J. Histochem. Cytochem. 51:1589-1600.

28. Moeller, M.J., and Holzman, L.B. 2006. Imaging podocyte dynamics. Nephron Exp. Nephrol. 103:e69-e74.

29. Sever, S., et al. 2006. Physical and functional connection between auxilin and dynamin during endocytosis. EMBO J. 25:4163-4174.

30. Kim, J.M., et al. 2003. CD2-associated protein haploinsufficiency is linked to glomerular disease susceptibility. Science. 300:1298-1300.

31. Eyre, J., et al. 2006. Statin-sensitive endocytosis of albumin by glomerular podocytes. Am. J. Physiol. Renal Physiol. 292:F674-F681.

32. Mundel, P., et al. 1997. Rearrangements of the cytoskeleton and cell contacts induce process formation during differentiation of conditionally immortalized mouse podocyte cell lines. Exp. Cell Res. 236:248-258.

33. Ishidoh, K., and Kominami, E. 1994. Multi-step processing of procathepsin $\mathrm{L}$ in vitro. FEBS Lett. 352:281-284.

34. Hsieh, C.S., deRoos, P., Honey, K., Beers, C., and Rudensky, A.Y. 2002. A role for cathepsin L and cathepsin $\mathrm{S}$ in peptide generation for MHC class II presentation. J. Immunol. 168:2618-2625.

35. Regele, H.M., et al. 2000. Glomerular expression of dystroglycans is reduced in minimal change nephrosis but not in focal segmental glomerulosclerosis. J. Am. Soc. Nephrol. 11:403-412.

36. Damke, H., Baba, T., Warnock, D.E., and Schmid, S.L. 1994. Induction of mutant dynamin specifically blocks endocytic coated vesicle formation. J. Cell Biol. 127:915-934.

37. Kim, S.W., et al. 2004. Increased expression and apical targeting of renal ENaC subunits in puromycin aminonucleoside-induced nephrotic syndrome in rats. Am. J. Physiol. Renal Physiol. 286:F922-F935.

38. Schmid, H., et al. 2003. Gene expression profiles of podocyte-associated molecules as diagnostic markers in acquired proteinuric diseases. J. Am. Soc. Nephrol. 14:2958-2966.

39. Damke, H., et al. 2001. Expression, purification, and functional assays for self-association of dynamin-1. Methods Enzymol. 329:447-457. 